\title{
Risk factor analysis for progressive spinal deformity after resection of intracanal tumors- a retrospective study of 272 cases
}

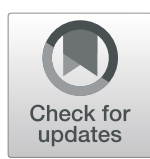

Pangbo Wang, Kang Ma, Tunan Chen, Xingsen Xue, Dada Ma, Shi Wang, Xin Chen, Hui Meng, Gaoyu Cui, Boyuan Gao, Jiangkai Lin, Hua Feng ${ }^{*}$ and Weihua Chu*

\begin{abstract}
Background: Progressive spinal deformity has become a well-recognized complication of intracanal tumors resection. However, the factors affecting post-operative spinal stability remain to be further research. Here, we described the current largest series of risk factors analysis for progressive spinal deformity following resection of intracanal tumors.

Methods: We retrospectively analyzed the medical records of the patients with resection of intracanal tumors between January 2009 and December 2018. All patients who underwent resection of intracanal tumors performed regular postoperative follow-up were identified and included in the study. Clinical, radiological, surgical, histopathological, and follow-up data were collected. The incidence of postoperative progressive kyphosis or scoliosis was calculated. The statistical relationship between postoperative progressive spinal deformity and radiographic, clinical, and surgical variables was assessed by using univariate tests and multivariate logistic regression analysis.

Results: Two hundred seventy-two patients (mean age $42.56 \pm 16.18$ years) with median preoperative modified McCormick score of 3 met the inclusion criteria. Among them, 7(2.6\%)patients were found to have spinal deformity preoperatively, and the extent of spinal deformity in these 7 patients deteriorated after surgery. 36 (13.2\%) were new cases of postoperative progressive deformity. The mean duration of follow-up was 21.8 months (median 14 months, range 6-114 months). In subsequent multivariate logistic regression analysis, age $\leq 18$ years $(p=0.027)$, vertebral levels of tumor involvement $(p=0.019)$ and preoperative spinal deformity $(p=0.008)$ was the independent risk factors $(p<0.05)$, increasing the odds of postoperative progressive spinal deformity by 3.94-, 0.69- and 27.11-fold, respectively.

Conclusions: The incidence of postoperative progressive spinal deformity was 15.8\%, mostly in these patients who had younger age ( $\leq 18$ years), tumors involved in multiple segments and preoperative spinal deformity. The risk factors of postoperative progressive spinal deformity warrants serious reconsideration that when performing resection of spinal cord tumors in these patients with such risk factors, the surgeons should consider conducting follow-ups more closely, and when patients suffering from severe symptoms or gradually increased spinal deformity, surgical spinal fusion may be a more suitable choice to reduce the risk of reoperation and improve the prognosis of patients.
\end{abstract}

Keywords: Intracanal tumors, Progressive spinal deformity, Risk factors

\footnotetext{
*Correspondence: fenghua8888@vip.163.com; weihua9871@163.com Department of Neurosurgery, Southwest Hospital, Third Military Medical University (Army Medical University), No. 29, Gaotanyanzheng Street, Shapingba District, Chongqing 400038, China
}

(c) The Author(s). 2020 Open Access This article is distributed under the terms of the Creative Commons Attribution 4.0 International License (http://creativecommons.org/licenses/by/4.0/), which permits unrestricted use, distribution, and reproduction in any medium, provided you give appropriate credit to the original author(s) and the source, provide a link to the Creative Commons license, and indicate if changes were made. The Creative Commons Public Domain Dedication waiver (http://creativecommons.org/publicdomain/zero/1.0/) applies to the data made available in this article, unless otherwise stated. 


\section{Background}

Primary spinal cord tumors are rare, with an incidence of 0.76 per 100,000 in the United States [1]. Advances in intraoperative neuroelectrophysiological monitoring and microsurgical techniques have contributed to the success rate of spinal cord tumors (SCTs) resection, which increases long-term survival and improves the quality of life of patients with spinal cord tumors [2,3]. However, with improved survival and longer follow-up times, patients often develop progressive spinal deformity postoperatively in the years after surgery, and which cause postoperative pain, reoperation and neurologic compromise in patients. It is reported that incidence of spinal deformity following intradural spinal tumor resection up to $10 \%$ in adults and rates ranging from 16 to $100 \%$ in pediatric patients [4-7]. Some reports suggested that laminoplasty resulted in less spinal deformity for the partial restoration of the posterior tension band [4]. But recent studies indicated that the incidence of postoperative spinal deformity associated with laminoplasty is close to laminectomy [8-10]. In fact, the study about risk factors for progressive spinal deformity after spinal cord tumors resection using the laminoplasty has been conducted [11]. However, limited by small samples and absence of multivariate analysis in previous studies, the convincing risk factors are still unclear. We undertook this larger retrospective study to furthermore determine the risk factors which may result in the higher incidence of progressive spinal deformity after surgical treatment of intracanal tumors.

\section{Methods}

This research was approved by the Ethics Board of Southwest Hospital of Army Military Medical University in China. The medical records of all patients underwent intracanal tumors resection between January 2009 and December 2018 at Chongqing Southwest Hospital were retrospectively analyzed. All patients who underwent resection of intracanal tumors performed regular postoperative follow-up were identified and included in the study. Exclusion criteria included: (1) previous resection at the same location; (2) ever underwent tumor resection with concurrent fusion. 272 patients were identified and included in the study. All clinical and radiological variables of the patients were recorded. All the patients underwent preoperative and postoperative imaging assessments (plain lateral radiographs and MRI) and were followed up at 3-, 6-, 12-, 18-, and 24-month after surgery to assess the presence of tumor recurrence and spinal deformity. The key endpoint of this study was the occurrence of progressive spinal deformity (Fig. 1). Progressive spinal deformity was defined as the progression of kyphotic or scoliotic curves by at least $10^{\circ}$ on 2 or more consecutive radiographs. Preoperative coronal Cobb angles $>10^{\circ}$, less of cervical/lumbar lordosis and kyphosis of the cervical/thoracic/lumbar spine before $\mathrm{SCT}$ resection were classified as preoperative spinal deformity. Progressive spinal deformity was first treated conservatively with prolonged bracing for another 3 to 6 months. The fusion surgery would be considered if it continued to develop or had symptoms. Neurological examinations of patients preoperatively, at hospital discharge, and regular follow-up were recorded. Functional status was evaluated according to the modified McCormick scale (MMS) both preoperatively and at the last follow-up [12].

In most cases, gross-total resection of the tumor, defined as excision of $\geq 95 \%$ of the tumor or absence of residual enhancement on postoperative MRI, was performed. In other cases, subtotal resection (80-95\% resection) were made

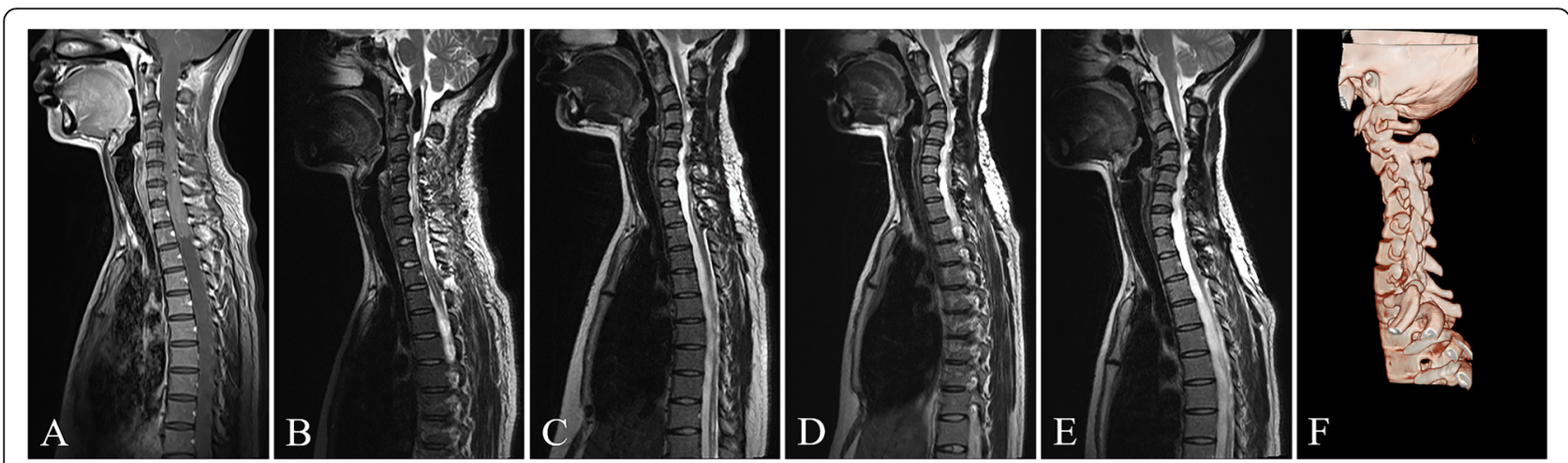

Fig. 1 The T2-weighted MR images shown was a 30-year-old woman who underwent resection of the ependymoma spanning from C3 to T2. a Preoperative MR images showed a huge tumor and the cervical spine had lost its normal curvature. $\mathbf{b}$ Postoperative MR images during postoperative hospitalization showed complete resection of spinal cord tumor and almost no change in cervical curvature. c The follow-up MR image showed progressive cervical kyphosis 6 months after the operation. $\mathbf{d}$, e The follow-up MR image showed deterioration of progressive cervical kyphosis 13 months and 24 months after the operation, respectively. $\mathbf{f}$ The CT three-dimensional reconstruction image showed the cervical kyphosis 24 months after the operation. At that time, the patient complained that her left upper limb was numb 
when the tumors invaded some more important tissues. Meanwhile, immediate postoperative MRI may detect retained fragment. Partial resection (removal of $<80 \%$ of the tumor) only occurred rarely when the tumor margin could not be clearly defined during surgery.

\section{Statistical analysis}

For intergroup comparison, the Student $t$ test was used for parametric data and the Mann-Whitney $U$ test for nonparametric data. Percentages were compared via the chi-square test or the Fisher exact test. In univariate analysis, variables with $\mathrm{p}<0.2$ entried into subsequent multivariate logistic regression analysis to determine the more important risk factors. Differences were considered significant with $p<0.05$. The results are presented as odds ratio (OR) and 95\% confidence intervals. Analyses were performed using IBM SPSS Statistics 20 (IBM Corp., Armonk, New York, USA).

\section{Results}

\section{Patient characteristics}

Two hundred and seventy-two patients underwent intracanal tumors resection were reviewed in this study. Demographic, clinical, and surgical features are summarized in Table 1. One hundred and twenty-seven (46.7\%) patients were male, $145(53.3 \%)$ patients were female, and their average age was $42.56 \pm 16.18$ years at the time of surgery. The average BMI index was $23.28 \pm 3.49$. One hundred and fifty-two patients (55.9\%) presented with back pain symptoms, 139(51.1\%) with motor weakness symptoms, 108(39.7\%) with sensory abnormal symptoms, and 47(17.3\%)with sphincter disturbances. The average symptom duration was 19.65(0-240) months. The median preoperative MMS score was 3 (interquartile range [IQR] 2-3). The number of patients with tumors located in the cervical spine, thoracic spine, lumbar spine, the cervicothoracic junction (C-7 and/or $\mathrm{T}-1)$, and the thoracolumbar junction (T-12 and/or L-1) were 50 (18.4\%), 103 (37.9\%), 70 (25.7\%), 20 (7.4\%), and 29 (10.7\%) respectively. Four (1.5\%) patients underwent preoperative biopsy. One patient underwent chemotherapy before surgery.

\section{Surgical and tumor characteristics}

The extent of resection of the laminae was depended on the vertebral levels of tumor involvement. Generally, keep the lamina as much as possible during the resection. Two hundred and fifty-three (93\%) underwent laminoplasty and 19 (7\%) underwent laminectomy. Gross total resection was achieved in 255 patients (93.8\%). Subtotal resection was achieved in 115 (5.5\%). Partial resection was achieved in 2(0.7\%). Pathology was intradural in 234 (86\%) and extradural in 38(14\%). Pathology included neurinoma in 123 (45.2\%), meningioma in 41 (15.1\%), ependymoma
Table 1 Baseline Patient Demographics, Comorbidities, and Operative Factors

\begin{tabular}{|c|c|}
\hline Variable & Value \\
\hline \multicolumn{2}{|l|}{ Sex, n(\%) } \\
\hline Female & $145(53.3 \%)$ \\
\hline Male & $127(46.7 \%)$ \\
\hline Age in yrs & $42.56 \pm 16.18$ \\
\hline BMI $\left(\mathrm{kg} / \mathrm{m}^{2}\right)$ & $23.28 \pm 3.49$ \\
\hline Symptom duration in mos & $19.65(0-240)$ \\
\hline \multicolumn{2}{|l|}{ Presenting symptoms } \\
\hline Back pain, n(\%) & $152(55.9 \%)$ \\
\hline Motor weakness, n (\%) & $139(51.1 \%)$ \\
\hline Sensory abnormal, n (\%) & $108(39.7 \%)$ \\
\hline Sphincter disturbances, n (\%) & $47(17.3 \%)$ \\
\hline Median preop MMS score (IQR) & $3(2-3)$ \\
\hline \multicolumn{2}{|l|}{ Location, n (\%) } \\
\hline Cervical & $50(18.4 \%)$ \\
\hline Cervicothoracic & $20(7.4 \%)$ \\
\hline Thoracic & $103(37.9 \%)$ \\
\hline Thoracolumbar & $29(10.7 \%)$ \\
\hline Lumbar & $70(25.7 \%)$ \\
\hline \multicolumn{2}{|c|}{ Vertebral levels of tumor involvement, $\mathrm{n}(\%)$} \\
\hline 1 & $69(25.4 \%)$ \\
\hline 2 & $136(50 \%)$ \\
\hline 3 & $39(14.3 \%)$ \\
\hline 4 & $15(5.5 \%)$ \\
\hline 5 & $3(1.1 \%)$ \\
\hline 6 & $2(0.7 \%)$ \\
\hline 7 & $4(1.5 \%)$ \\
\hline 8 & $1(0.4 \%)$ \\
\hline 12 & $3(1.1 \%)$ \\
\hline \multicolumn{2}{|l|}{ Previous treatment, n(\%) } \\
\hline Biopsy & $4(1.5 \%)$ \\
\hline Chemotherapy & $1(0.4 \%)$ \\
\hline \multicolumn{2}{|l|}{ Preop spinal deformity, n(\%) } \\
\hline No & $275(97.4 \%)$ \\
\hline Yes & $7(2.6 \%)$ \\
\hline \multicolumn{2}{|l|}{ Postop spinal deformity, n(\%) } \\
\hline No & $229(84.2)$ \\
\hline Yes & $43(15.8)$ \\
\hline
\end{tabular}

in 23 (8.5\%), cyst in 15 (5.5\%), angioma in 19 (7\%), and others in 51 (18.8\%) (Table 2).

\section{Postoperative outcomes and complications}

Surgical site infection occurred in 7 patients (2.6\%). Incisional cerebrospinal fluid (CSF) leak occurred in 9(3.3\%). 
Table 2 Surgical and tumor characteristics

\begin{tabular}{|c|c|}
\hline \multicolumn{2}{|c|}{ Sugery methods (laminectomy or laminoplasty) } \\
\hline laminoplasty & $253(93 \%)$ \\
\hline laminectomy & $19(7 \%)$ \\
\hline \multicolumn{2}{|c|}{ Extent of Surgery resection (no. of spinal levels) } \\
\hline 1 & $53(19.5 \%)$ \\
\hline 2 & $151(55.5 \%)$ \\
\hline 3 & $44(16.2 \%)$ \\
\hline 4 & $16(5.9 \%)$ \\
\hline 5 & $3(1.1 \%)$ \\
\hline 7 & $3(1.1 \%)$ \\
\hline 8 & $1(0.4 \%)$ \\
\hline 10 & $1(0.4 \%)$ \\
\hline \multicolumn{2}{|c|}{ Extent of tumor resection } \\
\hline GTR & $255(93.8 \%)$ \\
\hline STR & $15(5.5 \%)$ \\
\hline Partial resection & $2(0.7 \%)$ \\
\hline \multicolumn{2}{|c|}{ Intramedullary or Extramedullary, n(\%) } \\
\hline Intramedullary & $45(16.5 \%)$ \\
\hline Extramedullary & $237(83.5 \%)$ \\
\hline \multicolumn{2}{|l|}{ Surgeon, n (\%) } \\
\hline Dr. Lin & $98(36 \%)$ \\
\hline Dr. Meng & $50(18.4 \%)$ \\
\hline Dr. Cui & $38(14 \%)$ \\
\hline Dr. Gao & $36(13.2 \%)$ \\
\hline Dr. Wu & $25(9.2 \%)$ \\
\hline Other & $25(9.2 \%)$ \\
\hline \multicolumn{2}{|l|}{ Pathology, n (\%) } \\
\hline Neurinoma & $123(45.2 \%)$ \\
\hline Meningioma & 41 (15.1\%) \\
\hline Ependymoma & $23(8.5 \%)$ \\
\hline Cyst & 15 (5.5\%) \\
\hline Angioma & $19(7 \%)$ \\
\hline Other & 51 (18.8\%) \\
\hline
\end{tabular}

Neurologic complications, such as the emerging sphincter disturbances, sensory abnormal symptoms and even paraplegia, during hospitalization occurred in 19(7\%). The mean postoperative length of hospital stay was $16.79 \pm 8.34$ days. The average follow-up time was 21.8(6-114) mouths. Two hundred fifty-six people underwent postoperative brace fixation. The median postoperative MMS score at last follow-up was 1 (interquartile range [IQR] 1-1) (Table 3).

\section{Incidence of progressive spinal deformity}

Forty-three (15.8\%) patients developed progressive radiographic deformity within a mean of 13.2 months after
Table 3 Postoperative outcomes and complications

\begin{tabular}{ll}
\hline Surgical site infection, $\mathrm{n}(\%)$ & $7(2.6 \%)$ \\
\hline Incisional CSF leak, $\mathrm{n}(\%)$ & $9(3.3 \%)$ \\
Neurologic complications during hospitalization, $\mathrm{n}(\%)$ & $19(7 \%)$ \\
Postoperative length of hospital stay, $\mathrm{n}$ & $16.79 \pm 8.34$ \\
Median MMS score at last FU (IQR) & $1(1-1)$ \\
Mean FU in mos (range) & $21.82(6-114)$ \\
Time of spinal deformity in mos (range) & $13.23(2-60)$ \\
Postoperative brace fixation, $\mathrm{n}(\%)$ & $256(94.1 \%)$ \\
\hline
\end{tabular}

surgery. Among them, there were 26 adult ( $>18$ years old) patients, accounting for $10.8 \%$ of all 241 adult patients, and 17 children ( $\leq 18$ years of age), accounting for $54.8 \%$ of the 31 pediatric patients (Fig. 2). Among these 43 patients, 30 developed progressive kyphosis, and 13 developed progressive lordosis. Meanwhile, 7 patients presented with preoperative spinal deformity, and the extent of spinal deformity were deteriorated after surgery in all of them (Table 4). Four (9.3\%) patients with radiographic spinal deformity had symptoms and the others did not. Two (4.7\%) patients underwent spinal fusion surgery (Table 4).

\section{Risk factors for progressive spinal deformity}

In the univariate analysis, age $(p=0.000), \operatorname{sex}(p=0.191)$, $\operatorname{BMI}(p=0.000)$, symptom duration in mouths $(p=0.000)$, median preop MMS $\operatorname{score}(p=0.019)$, location of tumor $(p=0.151)$, vertebral levels of tumor involvement $(p=$ $0.005)$, preoperative $\operatorname{biopsy}(p=0.013)$, preoperative spinal deformity $(p=0.000)$, extent of surgery resection involvement $(p=0.000)$, $\operatorname{surgeon}(p=0.078)$, $\operatorname{pathology}(p=0.085)$, median MMS score at last follow-up $(p=0.114)$, and intramedullary or $\operatorname{not}(p=0.082)$ with a $P$ value $<0.2$ were identified as factors associated with postoperative progressive spinal deformity (Table 5). In subsequent multivariate logistic regression analysis, age $<18$ years $(p=0.027)$, vertebral levels of tumor involvement $(p=0.019)$ and preoperative spinal deformity $(p=0.008)$ were the independent risk factors $(p<0.05)$, increasing the odds of postoperative

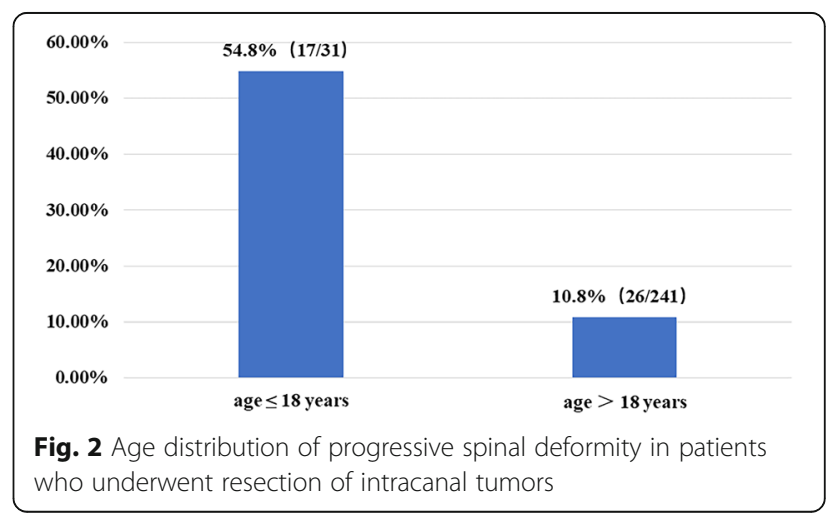




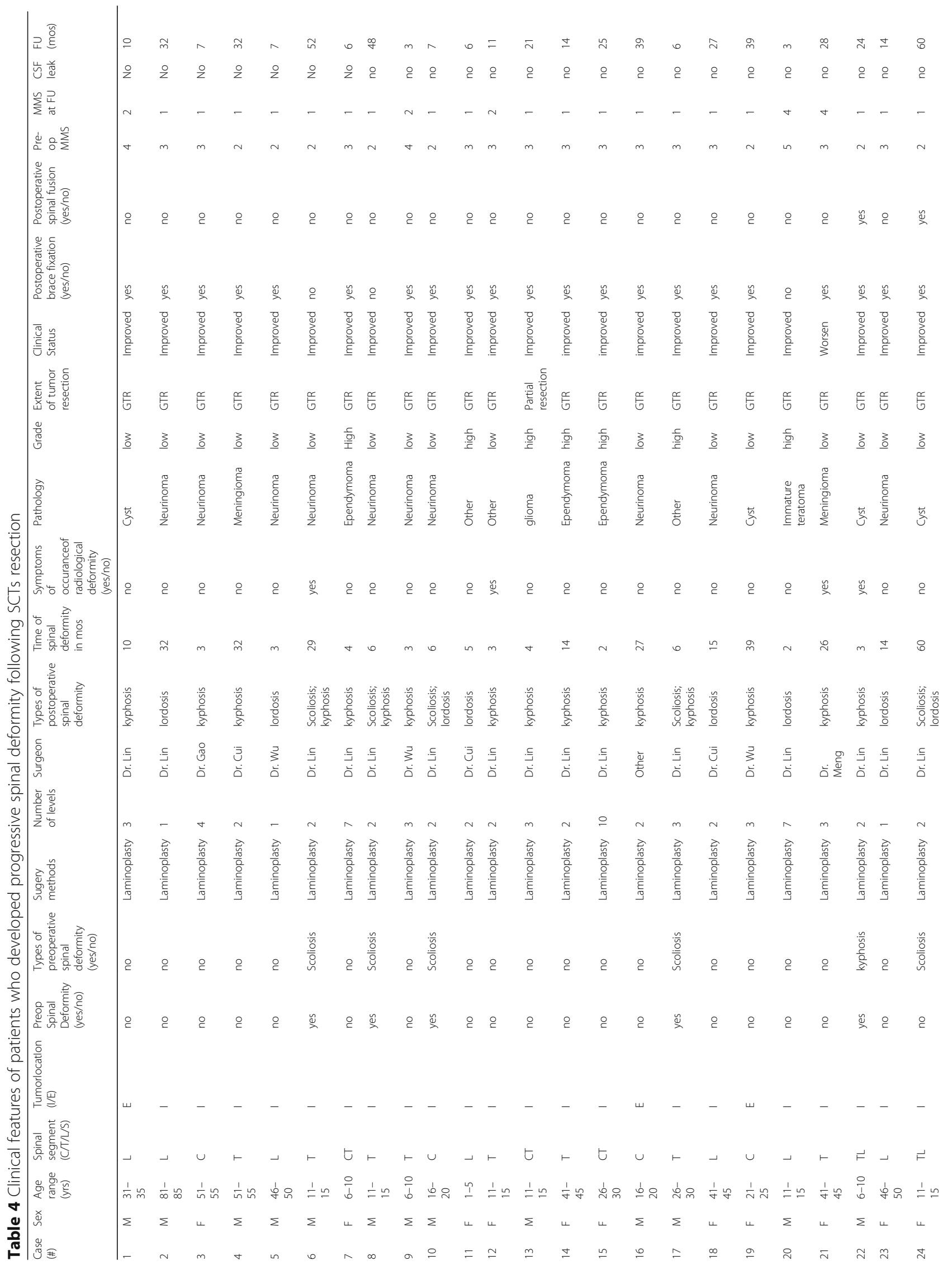




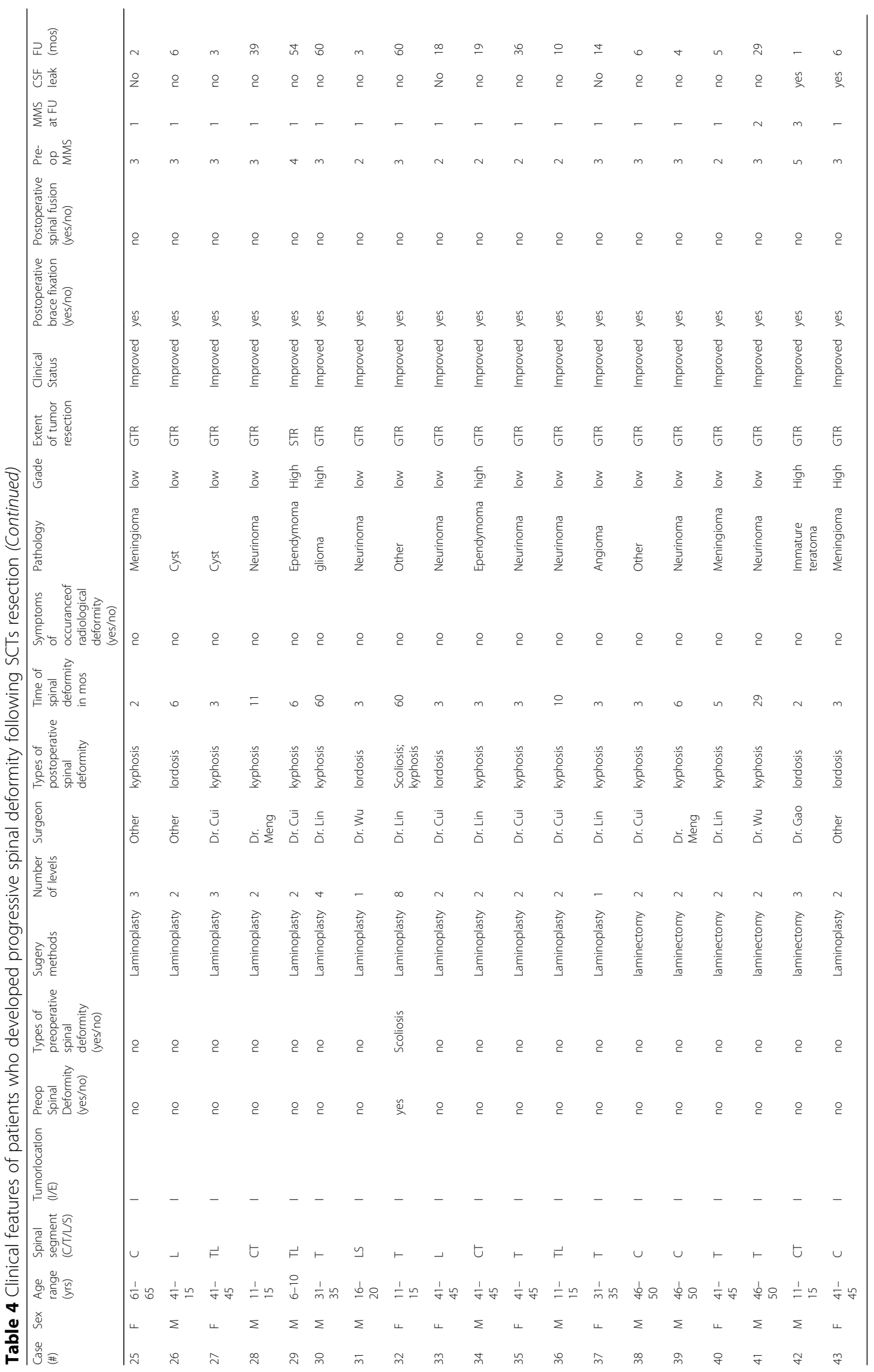


progressive spinal deformity by $3.94-, 0.69$ - and 27.11 -fold, respectively (Table 6).

\section{Discussion}

Postoperative progressive spinal deformity has been reported as an important complication following intracanal tumors resection. Deformity may develop progressively within many years after surgery and affect the final outcomes of patients [7]. However, opinions varied about the risk factors for postoperative progressive spinal deformity [5, 6]. Since first described in 1976 [13], laminoplasty has gradually replaced laminectomy for the less damages to the structure of the vertebral body and lower incidence of postoperative complications, such as incisional CSF leak [10]. However, some studies reported that laminoplasty was not associated with improvement in postoperative deformity after tumor resection $[8,10]$. Here, we analyzed the risk factors for postoperative spinal deformity following intracanal tumors resection, hoping to arouse the attention of the surgeons to reduce the occurrence of such complication. For those patients who had more risk factors of progressive spinal deformity, spinal fusion surgery

Table 5 Univariate analysis for predicting risk factors of progressive spinal deformity

\begin{tabular}{ll}
\hline Variable & $p$ value \\
\hline Sex & $\mathbf{0 . 1 9 1}$ \\
Bge & $\mathbf{0 . 0 0 0}$ \\
Symptom duration in mos & $\mathbf{0 . 0 0 0}$ \\
Presenting symptoms & $\mathbf{0 . 0 0 0}$ \\
Back pain & \\
Motor weakness & 0.497 \\
Sensory abnormal & 0.181 \\
Sphincter disturbances & 0.166 \\
Median preop MMS score & 0.850 \\
Location of tumor & $\mathbf{0 . 0 1 9}$ \\
Vertebral levels of tumor involvement & $\mathbf{0 . 1 5 1}$ \\
Previous treatment & $\mathbf{0 . 0 0 5}$ \\
Biopsy & \\
Chemotherapy & $\mathbf{0 . 0 1 3}$ \\
Preop spinal deformity & 1.000 \\
Extent of Surgery resection involvement & $\mathbf{0 . 0 0 0}$ \\
Extent of tumor resection & $\mathbf{0 . 0 0 0}$ \\
Intramedullary or Extramedullary & 0.750 \\
Surgeon & $\mathbf{0 . 0 8 2}$ \\
Pathology & $\mathbf{0 . 0 7 8}$ \\
Median MMS score at last FU & $\mathbf{0 . 0 8 5}$ \\
$\mathbf{0 . 1 1 4}$ \\
\hline set in bold are staistily siniffant
\end{tabular}

Data set in bold are statistically significant may be seriously considered, and close follow-up should be given to those who did not undergo this procedure.

In this research, 272 patients with resection of intracanal tumors were presented and risk factors of progressive spinal deformity were evaluated. After an average of 21.8 months of follow-up, the overall incidence of postoperative progressive spinal deformity was $15.8 \%$, which was comparable to previously reported incidence. We included the current most factors to analyze. Our research revealed that age $\leq 18$ years $(p=0.027)$, vertebral levels of tumor involvement $(p=0.019)$ and preoperative spinal deformity $(p=0.008)$ was the independent risk factors $(p<0.05)$, increasing the odds of postoperative progressive spinal deformity by 3.94-, 0.69 - and 27.11-fold, respectively. Meanwhile, the patients with progressive spinal deformity had a trend of increased postoperative median MMS score at last follow-up $(p=0.199)$ and neurologic complications. To date, this is the largest reported risk factor analysis case series in this field. Not only does it contain the largest number of cases, but also the factors. Moreover, it involved intramedullary and extramedullary tumors.

Papagelopoulos et al. [11, 14] reported that the incidence of spinal column deformity was $33 \%$ in children and adolescents while $8 \%$ in young adults. Recently, Wei Shi et al. [11] reported that patient age $\leq 25$ was the main significant predictive risk factor for postoperative spinal deformity. These data were consistent with our results that pediatric patients ( $\leq 18$ years of age) were more likely to suffer from postoperative progressive spinal deformity than the older adults (> 18 years of age). We speculated that the pediatric patient's immature skeletal system as well as surgery itself may change the mechanics of the spine, contributing to this phenomenon. In addition, because the growth rate of bone growth in children was greater than the spinal cord, adhesions in the postoperative area may cause a phenomenon similar with tethered cord syndrome, which caused related muscle neurotrophic decline that contributed to the development of spinal deformity.

Many previous studies demonstrated that extent of surgery resection (no. of spinal levels) was related to progressive spinal deformity. Katsumi et al. [15] revealed that age at operation, preoperative curvature in neutral position, number of removed laminas, C2 laminectomy, and destruction of facet joints are the risk factors that are involved in the pathogenetic mechanism of cervical instability. However, in our research, our data showed that not the extent of surgery resection, but the vertebral levels of tumor involvement may cause instability of the spine. The study revealed the average level of tumor involvement was 3.4 in patients who had progressive spinal deformity, comparing with 2 who had not. The risk factor of the vertebral levels of tumor involvement increased the odds of postoperative progressive spinal deformity by 0.69 - fold. The more levels of tumor 
Table 6 Multivariate logistic regression analysis for predicting risk factors of progressive spinal deformity in patients who underwent laminoplasty or laminectomy

\begin{tabular}{|c|c|c|c|}
\hline Variable & OR & $95 \% \mathrm{Cl}$ & $p$ value \\
\hline Sex & 0.812 & $0.325-2.033$ & 0.657 \\
\hline Age $\leq 18$ years & 3.941 & $1.165-13.327$ & 0.027 \\
\hline BMl & 1.105 & $0.971-1.256$ & 0.129 \\
\hline Symptom duration in mos & 1.006 & $0.99-1.022$ & 0.497 \\
\hline Median preop MMS score & 0.700 & $0.385-1.275$ & 0.244 \\
\hline Location of tumor & & & 0.413 \\
\hline Cervical & 2.628 & $0.712-9.706$ & 0.147 \\
\hline Cervicothoracic & 0.743 & $0.164-3.358$ & 0.699 \\
\hline Thoracic & 1.650 & $0.526-5.175$ & 0.39 \\
\hline Thoracolumbar & 2.436 & $0.527-11.263$ & 0.255 \\
\hline Vertebral levels of tumor involvement & 0.697 & $0.516-0.942$ & 0.019 \\
\hline Previous treatment & 2.703 & $0.121-60.35$ & 0.53 \\
\hline Preop spinal deformity & 27.112 & $2.408-305.316$ & 0.008 \\
\hline Extent of Surgery resection involvement & 1.061 & $0.691-1.63$ & 0.785 \\
\hline Surgeon & & & 0.226 \\
\hline Dr. Lin & 0.739 & $0.168-3.247$ & 0.688 \\
\hline Dr. Meng & 2.490 & $0.393-15.763$ & 0.332 \\
\hline Dr. Cui & 0.472 & $0.102-2.19$ & 0.338 \\
\hline Dr. Gao & 2.844 & $0.404-20.005$ & 0.294 \\
\hline Dr. Wu & 0.802 & $0.144-4.46$ & 0.801 \\
\hline Pathology & & & 0.634 \\
\hline Neurinoma & 0.443 & $0.14-1.407$ & 0.167 \\
\hline Meningioma & 0.375 & $0.087-1.612$ & 0.187 \\
\hline Ependymoma & 0.478 & $0.104-2.2$ & 0.343 \\
\hline Cyst & 0.378 & $0.074-1.948$ & 0.245 \\
\hline Angioma & 1.156 & $0.121-11.085$ & 0.9 \\
\hline Median MMS score at last FU & 0.852 & $0.403-1.802$ & 0.674 \\
\hline Intramedullary or Extramedullary & 0.497 & $0.188-1.312$ & 0.158 \\
\hline
\end{tabular}

Data set in bold are statistically significant

involvement, the more severe compression of the spinal cord, which may led to neurotrophic decline that aggravated the occurrence of spinal deformity.

Preoperative spinal deformity was independently associated with development of postoperative spinal deformity [16]. Similarly, Kaptain GJ et al. [11, 17] reported that the presence of preoperative spinal deformity was the factor most significantly related to the risk of developing progressive spinal deformity. Our research got the same conclusion. Preoperative spinal deformity even increased the odds of postoperative progressive spinal deformity by 27.11 -fold, and it was the biggest risk factor in the occurrence of postoperative spinal deformity. Preoperative spinal deformity may partly result from the spinal cord compression by the tumors, especially when the tumors invaded into the anterior horn region, which in turn led to neurotrophic disorders of the paravertebral muscles in the corresponding segments. The imbalance of paravertebral muscle caused a decrease in the stability of the spine. Eventually it led to progressive deformity. The operation inevitably damaged the posterior ligamentous complex and paraspinal muscles, which would further aggravate the preoperative spinal instability.

Riseborough et al. [18] reported that the greater amount of irradiation could lead to more severe deformity of the spine. Although the prior radiotherapy was not analyzed because of few relevant cases in our study, we found the patients with spinal deformity were more likely to suffer from preoperative puncture or biopsy, which might destroy the stability of the spine to some extent. Moreover, in the univariate analysis, extent of surgery resection involvement was also significantly higher in patients with spinal deformity than that without spinal deformity. However, in subsequent multivariate analysis, we found that compared 
with younger age and preoperative spinal deformity, the extent of surgery resection involvement contributed little to postoperative progressive spinal deformity. Many previous studies revealed that number of laminae resected played a role in the development of postoperative spinal deformity [6]. Here, we recommended that when encountering the tumors involved in multiple segments, under the premise of ensuring complete resection, minimize the number of laminae resected to minimize the loss of spinal stability.

Furthermore, the pathology of the tumors, location of tumor and the surgeons may influence the development of postoperative spinal deformity $[16,19]$. Our research also showed this trend (pathology, $p=0.085$; surgeon, $p=0.078$ ), but they did not reach statistical significance. In addition, our study showed that methods (laminectomy or laminoplasty, $p=0.746$ ) didn't affect the occurrence of postoperative progressive spinal deformity.

\section{Conclusions}

We found that the patients who had younger age $(<18$ years), tumors involved in multiple segments and preoperative spinal deformity had more risks of having postoperative progressive spinal deformity. The risk factors of postoperative progressive spinal deformity warrant serious reconsideration that when performing resection of intracanal tumors in these patients with more risk factors, the surgeons should seriously consider to conduct follow-up more closely or provide surgical fusion in order to reduce the risk of reoperation and improve the prognosis of patients.

\section{Abbreviations}

BMI: Body Mass Index; CSF: Cerebrospinal fluid; CT: Computed Tomography; IQR: Interquartile range; MMS: McCormick scale; MR images: Magnetic Resonance Images; MRI: Magnetic Resonance Imaging; OR: Odds ratio; SCTs: Spinal cord tumors

\section{Acknowledgements}

Not applicable.

\section{Authors' contributions}

All authors have read and approved the final manuscript. HF and WC designed and approved the entire study; PW prepared the draft; TC, XX,DM, SW, XC collected the data and revised the draft; HM, GC, BG and JL collected the data; PW, KM, and TC analyzed the data; KM and WC revised the manuscript; and PW, HF and WC performed the statistical analysis and revised the manuscript.

\section{Funding}

This research was supported by grants from the Collaborative Innovation Center for Brain Science of Chongqing (NO.4174D7) and the Technology Innovation and Application Demonstration Project of Chongqing (NO. cstc2018jscx-msybX0092), the Clinical New Technology Key Project of S outhwest Hospital (NO. SWH2016JSTSZD-04, SWH2017ZDCX2010).

\section{Availability of data and materials}

All the medical records of the patients underwent SCTs resection between January 2009 and December 2018 are from the medical record system of Chongqing Southwest Hospital. We organized and categorized the data to make it easier to access and analyze. If anyone would like to access to the original data, please contact us.
Ethics approval and consent to participate

This research was approved by the Ethics Board of Southwest Hospital of Army Military Medical University in China.

Consent for publication

Not applicable.

\section{Competing interests}

The authors declare that they have no competing interests.

Received: 15 August 2019 Accepted: 29 December 2019

Published online: 23 January 2020

\section{References}

1. Schellinger KA, et al. Descriptive epidemiology of primary spinal cord tumors. J Neuro-Oncol. 2008;87(2):173-9.

2. Jallo Gl, Freed D, Epstein F. Intramedullary spinal cord tumors in children. Childs Nerv Syst. 2003;19(9):641-9.

3. Jallo Gl, Kothbauer KF, Epstein FJ. Intrinsic spinal cord tumor resection. Neurosurgery. 2001;49(5):1124-8.

4. de Jonge $\mathrm{T}$, et al. Late-onset spinal deformities in children treated by laminectomy and radiation therapy for malignant tumours. Eur Spine J. 2005;14(8):765-71.

5. Fassett DR, et al. Cervical spine deformity associated with resection of spinal cord tumors. Neurosurg Focus. 2006;20(2):E2.

6. Sciubba DM, et al. Factors associated with cervical instability requiring fusion after cervical laminectomy for intradural tumor resection. J Neurosurg Spine. 2008;8(5):413-9.

7. McGirt MJ, et al. Incidence of spinal deformity after resection of intramedullary spinal cord tumors in children who underwent laminectomy compared with laminoplasty. J Neurosurg Pediatr. 2008;1(1):57-62.

8. Ratliff JK, Cooper PR. Cervical laminoplasty: a critical review. J Neurosurg. 2003;98(3 Suppl):230-8.

9. Hersh DS, et al. Instrumented fusion for spinal deformity after laminectomy or laminoplasty for resection of intramedullary spinal cord tumors in pediatric patients. Neurosurg Focus. 2017;43(4):E12.

10. McGirt MJ, et al. Short-term progressive spinal deformity following laminoplasty versus laminectomy for resection of intradural spinal tumors: analysis of 238 patients. Neurosurgery. 2010;66(5):1005-12.

11. Shi W, et al. Risk factor analysis of progressive spinal deformity after resection of intramedullary spinal cord tumors in patients who underwent laminoplasty: a report of 105 consecutive cases. J Neurosurg Spine. 2019:1-9.

12. McCormick PC, et al. Intramedullary ependymoma of the spinal cord. J Neurosurg. 1990;72(4):523-32.

13. Raimondi AJ, Gutierrez FA, Di Rocco C. Laminotomy and total reconstruction of the posterior spinal arch for spinal canal surgery in childhood. J Neurosurg. 1976;45(5):555-60.

14. Papagelopoulos PJ, et al. Spinal column deformity and instability after lumbar or thoracolumbar laminectomy for intraspinal tumors in children and young adults. Spine (Phila Pa 1976). 1997:22(4):442-51.

15. Katsumi Y, Honma T, Nakamura T. Analysis of cervical instability resulting from laminectomies for removal of spinal cord tumor. Spine (Phila Pa 1976). 1989;14(11):1171-6.

16. Ahmed $\mathrm{R}$, et al. Long-term incidence and risk factors for development of spinal deformity following resection of pediatric intramedullary spinal cord tumors. J Neurosurg Pediatr. 2014;13(6):613-21.

17. Kaptain GJ, et al. Incidence and outcome of kyphotic deformity following laminectomy for cervical spondylotic myelopathy. J Neurosurg. 2000;93(2 Suppl):199-204.

18. Riseborough EJ, et al. Skeletal alterations following irradiation for Wilms' tumor: with particular reference to scoliosis and kyphosis. J Bone Joint Surg Am. 1976;58(4):526-36.

19. Aronson DD, et al. Instability of the cervical spine after decompression in patients who have Arnold-Chiari malformation. J Bone Joint Surg Am. 1991; 73(6):898-906.

\section{Publisher's Note}

Springer Nature remains neutral with regard to jurisdictional claims in published maps and institutional affiliations. 